Check for updates

Cite this: RSC Adv., 2018, 8, 3789

Received 8th October 2017

Accepted 22nd December 2017

DOI: 10.1039/c7ra11051k

rsc.li/rsc-advances

\section{Single step electrodeposition process using ionic liquid to grow highly luminescent silicon/rare earth (Er, Tb) thin films with tunable composition}

\author{
Shibin Thomas, ${ }^{a}$ Jeremy Mallet, ${ }^{\star a}$ Hervé Rinnert ${ }^{\mathrm{b}}$ and Michael Molinari (iD *a
}

\begin{abstract}
A one-step method for the electrodeposition of silicon-erbium (Si/Er) and silicon-terbium (Si/Tb) thin films using room temperature ionic liquid (RTIL) has been successfully developed. By playing with the electrochemical parameters, the concentration of incorporated rare earth (RE) ions $\left(\mathrm{Er}^{3+}\right.$ and $\left.\mathrm{Tb}^{3+}\right)$ in the thin films can be tuned. The obtained thin films have been characterized by electron microscopy and composition analysis techniques. The structural quality of the obtained thin films is characterized by a uniform distribution of $\mathrm{Si}$ atoms and RE ions throughout the thickness. The study of the optical properties, carried out by photoluminescence (PL) spectroscopy, demonstrates the efficient optical activity of the films with typical Er and $\mathrm{Tb}$ luminescence at room temperature depending on the RE content. The deposition method described is a promising strategy for incorporating RE ions in semiconducting thin films to achieve materials for opto-electronic applications.
\end{abstract}

\section{Introduction}

Rare earth doped semiconductors are intensively studied due to their unique electronic and optical properties. ${ }^{\mathbf{1 , 2}} \mathrm{RE}$ ions are characterized by their narrow and efficient emission lines in the visible and near infrared (NIR) range which are almost insensitive to their host matrices due to the shielding effect of outer 5s and 5p electrons. Among the RE ions, $\mathrm{Er}^{3+}$ has gained more attention because of its highly efficient light emission at 1.53 $\mu \mathrm{m} .{ }^{3}$ Similarly, $\mathrm{Tb}^{3+}$ has strong radiative intra $4 \mathrm{f}$ transitions in the visible wavelengths close to the typical blue-green colour. ${ }^{4}$ So, materials incorporating these ions are considered as potential candidates in modern opto-electronics. As silicon is currently the most leading functional material for industrial applications, RE incorporation in Si represents a promising way of developing silicon based opto-electronics. RE incorporated Si materials are widely used for applications in telecommunication, ${ }^{5}$ photovoltaics ${ }^{6,7}$ and display applications such as electroluminescence ${ }^{\mathbf{8} 9}$ or Light Emitting Diodes (LEDs). ${ }^{\mathbf{1 0}}$

A great number of techniques have been developed to incorporate the RE ions into silicon, such as ion implantation, ${ }^{\mathbf{1 1}}$ magnetron co-sputtering ${ }^{\mathbf{1 2 , 1 3}}$ and plasma enhanced chemical vapour deposition (PECVD).. ${ }^{\mathbf{1 4 5}}$ However these current synthesis methods involve constraining deposition conditions such as high vacuum, high temperature, different steps of

${ }^{a}$ Laboratoire de Recherche en Nanosciences, LRN EA4682, Université de Reims Champagne-Ardenne, Campus Moulin de la Housse, BP 1039, 51687 Reims, France. E-mail: michael.molinari@univ-reims.fr; jeremy.mallet@univ-reims.fr

${ }^{b}$ Université de Lorraine, Institut Jean Lamour UMR CNRS 7198, 54506 Vandœuvre-lèsNancy Cedex, B.P. 70239, France growth and the use of potentially dangerous precursors which makes these processes complicated and expensive. Therefore, the development of low cost and non-constraining alternative techniques for the $\mathrm{RE}$ incorporation in $\mathrm{Si}$ is of primary importance.

Electrochemical growth methods have emerged as low cost techniques as it operates low temperatures and does not involve any high vacuum or other constraining conditions. Electrodeposition of metals and semiconductor compounds from aqueous electrolytes has been extensively studied by various researchers and it is currently a well-established field. However, elemental Si and RE metals cannot be electrodeposited from aqueous electrolytes due to their large reduction potential and also to the high reactivity of the common precursors such as $\mathrm{Si}$ or RE halides with water. Besides, the RE metals are highly corrosive in aqueous medium as they react with water to give hydrogen and metal hydroxides or oxides. ${ }^{16}$ Hence, the electrodeposition of $\mathrm{Si}$ and $\mathrm{RE}$ metals requires the use of a nonaqueous electrolytic medium such as RTILs, ${ }^{17-19}$ organic solvents ${ }^{20-22}$ or molten salts. ${ }^{23-25}$ Among these solvents, the RTILs offer a number of advantages such as wide electrochemical window, high ionic conductivity, superior thermal stability and negligible vapour pressure. ${ }^{26}$ In addition to being less corrosive than other non-aqueous electrolytes, RTILs allow deposition at relatively lower temperatures. Additionally, they offer high solubility to most of the semiconductor and reactive metal salts, including the salts of rare earth metals, facilitating their use as the solvent for electrodeposition.

There have been a number of reports on the electrodeposition of elemental Si or its alloys from RTILs. ${ }^{27-32}$ However, the use of RTILs for the deposition of RE metals is not well attended 
and there have been only very few attempts towards the realization of it. ${ }^{33,34} \mathrm{~A}$ comparison of the $\mathrm{Er}^{3+}$ electroreduction from different non-aqueous electrolytes including quaternary ammonium based ionic liquids has been reported recently by Small et al. ${ }^{35}$ however, obtaining RE deposits with high purity remains challenging. To our knowledge, there are no other reports on the use of RTILs for the electrodeposition of Er and $\mathrm{Tb}$, which are highly important dopants in Si based optoelectronic materials. These two RE metal ions differs in their optical emission properties, $\mathrm{Er}^{3+}$ emitting in the Near Infra-Red (NIR) and $\mathrm{Tb}^{3+}$ emitting in the visible range of the electromagnetic spectrum which enables to cover a large field of applications. Electrochemical incorporation of RE ions in silicon has been demonstrated in the literature, ${ }^{36-39}$ however, the technique is only limited to the porous $\mathrm{Si}$ (p-Si) systems which is a fragile material and suffers from instability issues to consider for optoelectronic applications. Additionally, the technique is a two-step approach where the $\mathrm{p}-\mathrm{Si}$ is fabricated by anodic etching process in the first step followed by the incorporation of RE ions by electrochemical polarisation. The involvement of multi-step fabrication routes and the requirement of potentially dangerous chemicals such as HF makes the process complex and inappropriate for large scale production.

The present study demonstrates the successful electrodeposition of metallic Er and Tb with high purity from RTIL for the first time, and develops a novel electrochemical approach for obtaining Si/RE thin films by co-depositing RE metals with Si. Besides, it is shown that the RE content in Si thin films can be tuned by controlling the electrochemical parameters. Finally, the luminescence properties of the deposited Si/RE thin films have been investigated to confirm the potential of the materials for applications in modern opto-electronics.

\section{Experimental}

For the present study, 1-butyl-1-methylpyrrolidinium bis(trifluoromethylsulfonyl)imide ([Py $\left.{ }_{1,4}\right]$ TFSI) ionic liquid purchased from Solvionic was used as the solvent for electrodeposition of $\mathrm{RE}$ metals and Si. The quality of $\left[\mathrm{Py}_{1,4}\right]$ TFSI given by the supplier is $99.99 \%$. In order to reduce the water content, the IL was dried under vacuum at $100{ }^{\circ} \mathrm{C}$ for at least 5 days. The drying of the IL was performed in an argon filled glove box (Innovative Technology) with oxygen and moisture content below $1 \mathrm{ppm}$. Silicon tetrachloride (99.998\%), erbium chloride (99.99\%) and terbium chloride (99.99\%) purchased from Sigma Aldrich were used as the precursors for silicon, erbium and terbium respectively.

All the electrochemical studies were performed inside an Argon filled glove box using a three electrode based electrochemical cell. n-Doped silicon (100) substrate was used as the working electrode for the deposition. Prior to use, the $\mathrm{Si}$ substrates were treated with ammonium fluoride-hydrofluoric acid mixture etching solution to remove the natural oxide $\left(\mathrm{SiO}_{x}\right)$ layer on the surface. Platinum wire was used as the quasireference electrode which provides relatively stable electrode potentials for the present electrochemical studies. A platinum wire was used as the counter electrode. Utmost care was given for the cleaning and drying of the electrochemical cell and the electrodes before performing the electrochemical experiments. All the electrochemical measurements were done using a Voltalab PGZ 100 potentiostat/galvanostat controlled by Voltamaster 4 software. The experiments were carried out at a controlled temperature of $70{ }^{\circ} \mathrm{C}$ which enables to limit possible heating effects during the process and thus enhances its reproducibility. The surface morphology of the deposited thin film was obtained by a Scanning Electron Microscopy (SEM, HITACHI S-3400N). The chemical composition of the deposit was analysed by Energy Dispersive X-ray spectroscopy (EDX) coupled to the SEM. The composition and homogeneity of the thin films were further analysed by Secondary Ion Mass Spectrometry (SIMS). The photoluminescence (PL) spectra were obtained using the $325 \mathrm{~nm}$ line of a He-Cd laser for the excitation and the sample emission was collected with a monochromator equipped with an InGaAs photomultiplier cooled at $140 \mathrm{~K}$.

\section{Results and discussion}

\subsection{Electrodeposition of $\mathrm{Si}$}

In order to study the electrochemical stability of the RTIL and to understand the electrochemical processes at the interface, Cyclic Voltammetry (CV) was performed. Fig. 1a shows the CV's of pure $\left[\mathrm{Py}_{1,4}\right]$ TFSI (dashed line) and $0.01 \mathrm{M} \mathrm{SiCl}_{4}$ in $\left[\mathrm{Py}_{1,4}\right]$ TFSI (solid line) recorded on $\mathrm{Si}(100)$ substrate at a scan rate of $10 \mathrm{mV}$ $\mathrm{s}^{-1}$. The CV of pure $\left[\mathrm{Py}_{1,4}\right]$ TFSI does not show any cathodic reduction peaks till $-3.5 \mathrm{~V}$, which indicates the stability of the IL in the cathodic scan. The rise of current below $-3.5 \mathrm{~V}$ could be attributed to the breakdown of the organic cation, i.e. the cathodic reduction of $\left[\mathrm{Py}_{1,4}\right]^{+}$cation. The $\mathrm{CV}$ of the $\left[\mathrm{Py}_{1,4}\right]$ TFSI confirms that the IL is pure, dry and electrochemically stable enough to be used as the solvent for electrodeposition. The electrochemical window of $\left[\mathrm{Py}_{1,4}\right]$ TFSI is calculated to be around $5 \mathrm{~V}$. The high electrochemical stability of the IL, especially in the cathodic regime, makes possible the electrodeposition of semiconductors and RE metals. As can be seen in the Fig. 1a, the $\mathrm{CV}$ of $0.01 \mathrm{M} \mathrm{SiCl}_{4}$ in $\left[\mathrm{Py}_{1,4}\right]$ TFSI exhibits two reduction peaks, observed at $-1 \mathrm{~V}$ and $-2.5 \mathrm{~V}$ in the cathodic scan. The origin of the reduction peak at $-1 \mathrm{~V}$ is not yet fully understood, however it could be related to some charging/discharging process occurring at the interface. In order to confirm that this reduction peak is not related to the electro reduction of $\mathrm{Si}$, electrodeposition has been done by applying potentials between $-1 \mathrm{~V}$ and $-2 \mathrm{~V}$. No observable deposits have been obtained on the substrate. The reduction peak at $-2.5 \mathrm{~V}$ is due to the bulk reduction of silicon onto the working electrode, which is confirmed by the EDX analysis of the yellowish white film obtained on the substrate.

Fig. 1b shows the top view SEM image of the Si deposit obtained by applying a constant potential of $-2.7 \mathrm{~V}$ for 1 hour at $70{ }^{\circ} \mathrm{C}$. The deposition leads to the formation of a homogeneous $\mathrm{Si}$ thin film on the electrode. The morphology of the deposit reveals the roughness of the film containing few cracks on the surface. These cracks observed at high magnification (Fig. 1b) could be a result of internal stresses during the deposition. EDX analysis (inset of Fig. 1b) performed simultaneously with SEM 

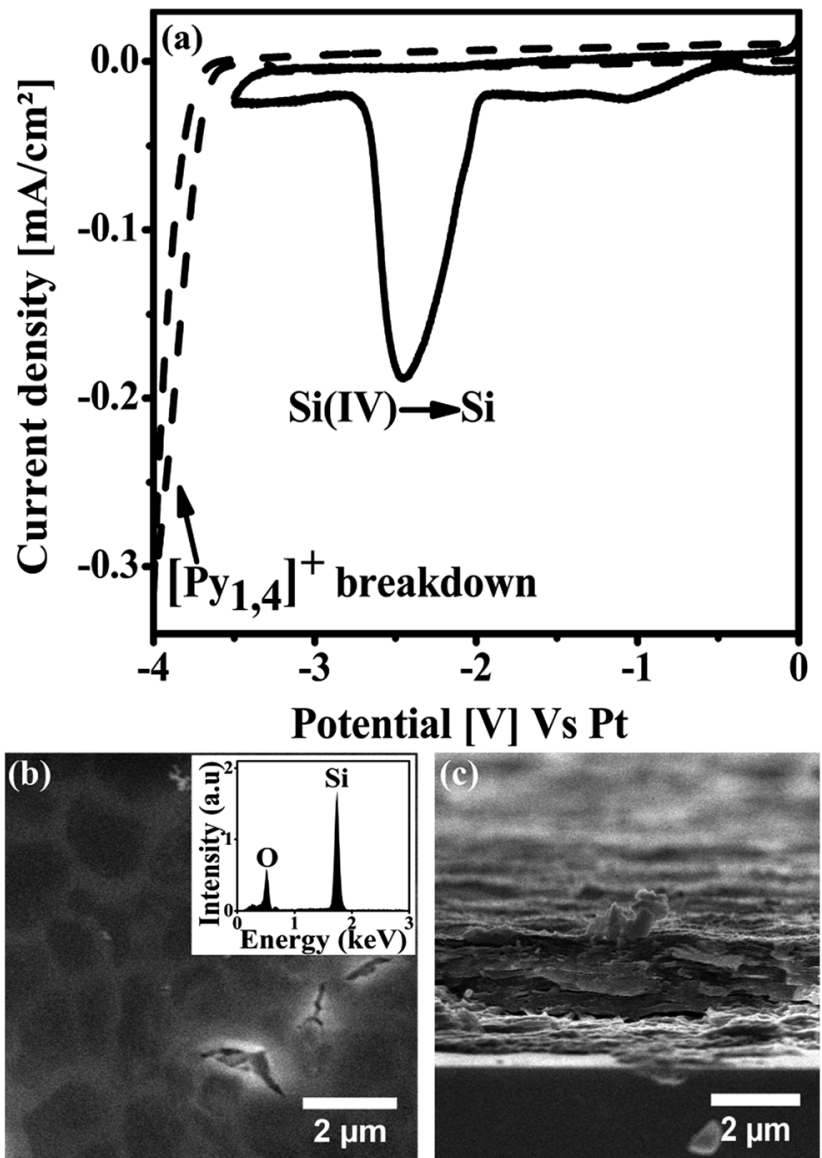

Fig. 1 (a) $\mathrm{CV}$ (scan rate of $10 \mathrm{mV} \mathrm{s}^{-1}$ ) of pure [Py $\left.\mathrm{P}_{1,4}\right] \mathrm{TFSI}$ (dashed line) and $\left[\mathrm{Py}_{1,4}\right] \mathrm{TFSI}$ with $0.01 \mathrm{M} \mathrm{SiCl}_{4}$ (solid line) on $\mathrm{Si}(100)$ substrate vs. Pt at $70{ }^{\circ} \mathrm{C}$. (b) Top view SEM image of the Si thin film obtained by potentiostatic deposition at $-2.7 \vee v s$. Pt. Inset shows the EDX profile of the Si deposit. (c) Cross-section SEM image of the Si thin film.

imaging shows that the thin film consists of only Si and O. No other impurities were detected in the detection limit of the EDX spectroscopy. The presence of oxygen is due to the oxidation of $\mathrm{Si}$ in air during the storage of deposit prior to the SEM and EDX observation. Fig. 1c shows the cross-section SEM image of the Si thin film. It is clear from the image that the thin film growth occurs in a laminar fashion resulting in a dense compact film at the end. The thickness of the deposit is measured to be $1.6 \mu \mathrm{m}$. Careful examinations of the SEM images, supported by the similarities of the present growth conditions with previous reports, ${ }^{27,28,40}$ suggest that the deposited $\mathrm{Si}$ is amorphous in nature. The above results shows that pure a-Si thin film was electrodeposited from $\left[\mathrm{Py}_{1,4}\right]$ TFSI, which is an important preliminary step for the further studies described in this article.

\subsection{Electrodeposition of $\mathrm{RE}(\mathrm{Er}, \mathrm{Tb})$ metals}

Prior to perform the co-deposition of $\mathrm{RE}$ metals with $\mathrm{Si}$, the possibility of electrodeposition of pure RE metals from RTIL has been studied. The results described below shows the successful electrodeposition of pure Er and Tb metals from RTIL.

3.2.1. Electrodeposition of pure Er. Fig. 2a shows the CV of $\left[\mathrm{Py}_{1,4}\right]$ TFSI with $0.01 \mathrm{M} \mathrm{ErCl}_{3}$ on $\mathrm{Si}(100)$ substrate vs. Pt at $70{ }^{\circ} \mathrm{C}$.
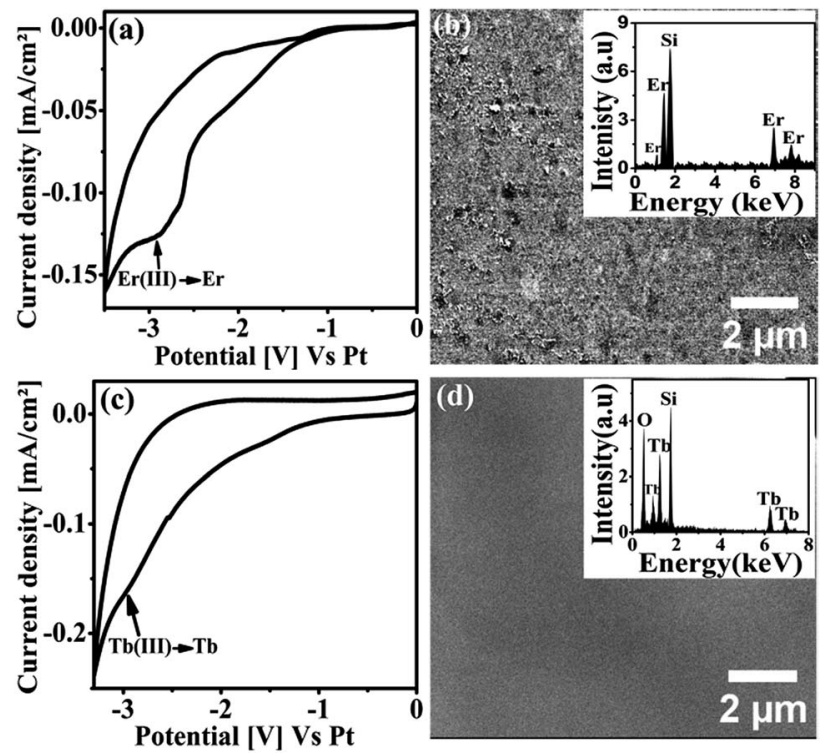

Fig. 2 (a) $\mathrm{CV}$ (scan rate of $10 \mathrm{mV} \mathrm{s}^{-1}$ ) of $\left[\mathrm{Py}_{1,4}\right] \mathrm{TFSI}$ with $0.01 \mathrm{M} \mathrm{ErCl}_{3}$ on $\mathrm{Si}(100)$ substrate vs. Pt at $70{ }^{\circ} \mathrm{C}$. (b) Top view SEM image of the $\mathrm{Er}$ thin film deposited by applying $-3.2 \mathrm{~V}$ vs. Pt. Inset shows the corresponding EDX spectrum (c) CV (scan rate of $10 \mathrm{mV} \mathrm{s}^{-1}$ ) of $\left[\mathrm{Py}_{1,4}\right]$ TFSI with $0.01 \mathrm{M} \mathrm{TbCl}_{3}$ on $\mathrm{Si}(100)$ substrate vs. Pt at $70{ }^{\circ} \mathrm{C}$. (d) Top view SEM image of $\mathrm{Tb}$ thin film deposited by applying $-3.2 \mathrm{~V} v \mathrm{v}$. Pt. Inset shows the EDX spectrum obtained from the deposit.

The CV has no significant reduction peaks till $-1 \mathrm{~V}$. A small increase in current density is observed from $-1 \mathrm{~V}$ to $-2.4 \mathrm{~V}$, which turns into a steep increase from $-2.5 \mathrm{~V}$ to $-2.7 \mathrm{~V}$ in the cathodic scan. The origin of these reduction currents is not well understood now and a detailed investigation on the electrochemical behaviour of $\mathrm{ErCl}_{3}$ in RTIL will be required, which is beyond the scope of this study. Electrodeposition has been done by applying potentials more positive than $-2.6 \mathrm{~V}$ and we neither observed any microscopic deposit nor a colour change on the substrate. The growth rate of Er above $-2.6 \mathrm{~V}$ could be too low to observe any deposit. The onset of Er metal reduction is observed at $-2.7 \mathrm{~V}$ in the $\mathrm{CV}$. The reduction plateau observed at $-3 \mathrm{~V}$ corresponds to the bulk reduction of Er metal onto the working electrode, which is confirmed by the successful electrodeposition of Er at this potential range. The rising current after $-3.2 \mathrm{~V}$ is due to the irreversible reduction of the organic cation in $\left[\mathrm{Py}_{1,4}\right]$ TFSI.

After identifying the reduction potential of Er from the CV, potentiostatic electrodeposition was performed by applying $-3.2 \mathrm{~V}$ for 1 hour onto $\mathrm{Si}$ (100) substrate using $0.01 \mathrm{M} \mathrm{ErCl}_{3}$ in $\left[\mathrm{Py}_{1,4}\right] \mathrm{TFSI}$ at $70{ }^{\circ} \mathrm{C}$. The surface morphology of the obtained deposit was characterized by the SEM. Fig. 2b shows the representative top view SEM image obtained from the metallic Er thin film. It can be observed from the image that the potentiostatic deposition leads to a homogeneous deposition of Er on the substrate. The surface of the metallic thin film is rough and contains few micrometre sized clusters. The chemical composition of the thin film was analysed by EDX (Fig. $2 b$ inset) which gave signals of mainly Er with no significant impurities or oxygen in the detection limit, meaning that the 
deposited thin film comprises of pure Er metal. The Si signal observed in the EDX spectrum is due to the Si (100) substrate used for deposition.

3.2.2. Electrodeposition of pure Tb. Fig. $2 \mathrm{c}$ shows the $\mathrm{CV}$ of $\left[\mathrm{Py}_{1,4}\right]$ TFSI with $0.01 \mathrm{M} \mathrm{TbCl}_{3}$ on $\mathrm{Si}(100)$ substrate $v$ s. $\mathrm{Pt}$ at $70^{\circ} \mathrm{C}$. Similar to the CV of $\mathrm{ErCl}_{3}$ in $\left[\mathrm{Py}_{1,4}\right]$ TFSI, the present CV also shows a small increase in current density from $-1.2 \mathrm{~V}$ to $-2.5 \mathrm{~V}$, the origin of which is unclear now and needs further investigation. The peak shoulder observed at $-3 \mathrm{~V}$ corresponds to the bulk reduction of $\mathrm{Tb}^{3+}$ ions into metallic $\mathrm{Tb}$. No observable deposit was obtained by applying potentials more positive than $-2.6 \mathrm{~V}$.

Metallic $\mathrm{Tb}$ was potentiostatically electrodeposited onto $\mathrm{Si}$ (100) substrate from $0.01 \mathrm{M} \mathrm{TbCl}_{3}$ in $\left[\mathrm{Py}_{1,4}\right]$ TFSI by applying $-3.2 \mathrm{~V}$ for 1 hour at $70^{\circ} \mathrm{C}$. Fig. $2 \mathrm{~d}$ shows the top view SEM image of the deposited $\mathrm{Tb}$ thin film. The thin film evolves as a smooth homogeneous layer on the substrate. The EDX analysis (Fig. 2d inset) reveals the presence of $\mathrm{Tb}$ and $\mathrm{O}$ in the thin film. Metallic $\mathrm{Tb}$ is well known for its affinity towards oxygen. ${ }^{41} \mathrm{The} \mathrm{Tb}$ deposit undergoes oxidation in air to form its oxides $\left(\mathrm{Tb}_{1-x} \mathrm{O}_{x}\right)$ as it is exposed to the ambient atmosphere. The $\mathrm{Si}$ signal is arising from the Si (100) substrate used. The result shows that pure $\mathrm{Tb}$ thin film is successfully electrodeposited from the RTIL, which turns into $\mathrm{Tb}_{1-x} \mathrm{O}_{x}$ once exposed to the air.

\subsection{Co-deposition of $\mathrm{RE}(\mathrm{Er}, \mathrm{Tb})$ metals with $\mathrm{Si}$}

Understanding the potential for RTILs in electrodepositing both $\mathrm{Si}$ and $\mathrm{RE} \mathrm{(Er,} \mathrm{Tb})$ metals is mandatory to study the possibility of co-depositing Si with RE metals, as the principle of the co-deposition is to use the two precursors ( $\mathrm{Si}$ and $\mathrm{RE}$ ) in the solution and to work at a given potential appropriate for the deposition of the two metals. The results of the investigation are described below.

3.3.1. Si/Er thin films. The co-deposition was performed using electrolytic solution containing both the $\mathrm{Si}$ and $\mathrm{Er}$ precursors. The solid line in Fig. 3a shows the $\mathrm{CV}$ of $\left[\mathrm{Py}_{1,4}\right] \mathrm{TFSI}$ with $0.01 \mathrm{M} \mathrm{SiCl}_{4}$ and $0.01 \mathrm{M} \mathrm{ErCl}_{3}$ on $\mathrm{Si}(100)$ substrate $v s$. Pt at $70{ }^{\circ} \mathrm{C}$. The dashed line in the graph represents the $\mathrm{CV}$ of $\left[\mathrm{Py}_{1,4}\right]$ TFSI with $0.01 \mathrm{M} \mathrm{SiCl}_{4}$ alone, given here for an easy comparison of the reduction processes. The electrolytic mixture of $0.01 \mathrm{M}$ $\mathrm{ErCl}_{3} / 0.01 \mathrm{M} \mathrm{SiCl}_{4}$ in $\left[\mathrm{Py}_{1,4}\right]$ TFSI contains two electro-active cations, $\mathrm{Si}^{4+}$ and $\mathrm{Er}^{3+}$ ions. Accordingly, the $\mathrm{CV}$ of the electrolyte shows two prominent reduction peaks; a peak shoulder at $-2.5 \mathrm{~V}$ and the other peak at $-3 \mathrm{~V}$ as can be identified from Fig. 3a. In comparison with the $\mathrm{CV}$ of $0.01 \mathrm{M} \mathrm{SiCl}_{4}\left[\mathrm{Py}_{1,4}\right] \mathrm{TFSI}$, it is clear that the peak shoulder at $-2.5 \mathrm{~V}$ corresponds to the bulk reduction of $\mathrm{Si}$. The additional peak present at $-3 \mathrm{~V}$ is assigned to the reduction of $\mathrm{Er}^{3+}$ ions. The current density recorded between $-1.2 \mathrm{~V}$ and $-2.2 \mathrm{~V}$ does not contribute to the reduction of any elements of interest for the present study.

The CV was used to determine the potential range for performing the co-deposition of $\mathrm{Si}$ with Er. The co-deposition of $\mathrm{Si} /$ Er thin film was done potentiostatically by applying $-3.2 \mathrm{~V}$ for 1 hour at $70{ }^{\circ} \mathrm{C}$. Fig. $3 \mathrm{~b}$ shows the top view SEM image of the deposited Si/Er thin film. It can be seen clearly from the image that the deposit comprises of a thin film homogeneously
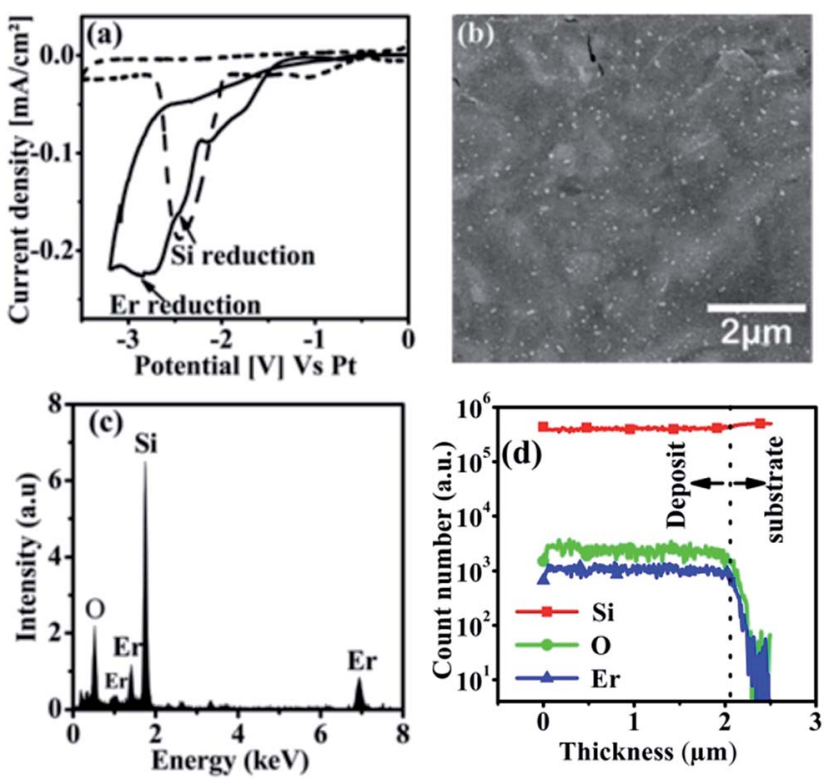

Fig. 3 (a) $\mathrm{CV}$ (scan rate of $10 \mathrm{mV} \mathrm{s}^{-1}$ ) of $\left[\mathrm{Py}_{1,4}\right] \mathrm{TFSI}$ with $0.01 \mathrm{M} \mathrm{SiCl}_{4}$ and $0.01 \mathrm{M} \mathrm{ErCl}_{3}$ (solid line) on $\mathrm{Si}(100)$ substrate vs. Pt at $70{ }^{\circ} \mathrm{C}$. The dashed line represents the $\mathrm{CV}$ of $\left[\mathrm{Py}_{1,4}\right]$ TFSI with $0.01 \mathrm{M} \mathrm{SiCl}_{4}$ alone. (b) Top view SEM image of the Si/Er thin film obtained by applying $-3.2 \mathrm{~V}$ vs. Pt. (c) The EDX spectrum obtained from the Si/Er thin film. (d) SIMS depth profile of the deposit.

covering the substrate with some roughness observed on the surface. The deposit grows uniformly in the beginning of the deposition to make a smooth thin film covering the electrode. As the deposition progresses, the higher electrical resistance of the deposited Si/Er layer and the internal stresses formed at the surface cause non-uniform distribution of the particles, leading to the formation of micro islands and small cracks on the surface. X-ray diffraction experiments (not shown here) shown that the deposited thin film is amorphous in nature. In order to confirm the presence of Er in the Si thin film, EDX analysis was performed on the deposit. Fig. 3c shows the EDX spectrum for the Si/Er deposit. The spectrum shows the signals corresponding to $\mathrm{Si}, \mathrm{O}$ and $\mathrm{Er}$ which indicates clearly the successful incorporation of Er in the Si thin film. The presence of oxygen is due to the unavoidable oxidation of $\mathrm{Si}$ in the atmosphere. An estimation of the elemental composition of the thin films using EDX shows that the content of Er in the thin film varies between 8-13 atomic percentages (at\%). In order to gain insights on the homogeneity of the thin film along the thickness, SIMS depth profile analysis has been performed on the deposit. Fig. 3d shows the SIMS depth profile of the Si/Er thin film. The depth profile reveals the signals of $\mathrm{Si}$, Er and $\mathrm{O}$. As can be seen from the spectrum, the thin film has uniform composition throughout the depth, demonstrated by the uniform ionic yields of $\mathrm{Si}$, Er and O starting from the uppermost surface till the substrate interface.

3.3.2. $\mathrm{Si} / \mathrm{Tb}$ thin films. A similar procedure has applied to co-deposit $\mathrm{Si}$ and Tb. Fig. $4 \mathrm{a}$ represents the $\mathrm{CV}$ of $\left[\mathrm{Py}_{1,4}\right] \mathrm{TFSI}$ with $0.01 \mathrm{M} \mathrm{SiCl}_{4}$ and $0.01 \mathrm{M} \mathrm{TbCl}_{3}$ (solid line) on $\mathrm{Si}$ (100) substrate vs. Pt at $70{ }^{\circ} \mathrm{C}$. In comparison with the CV of $0.01 \mathrm{M}$ 


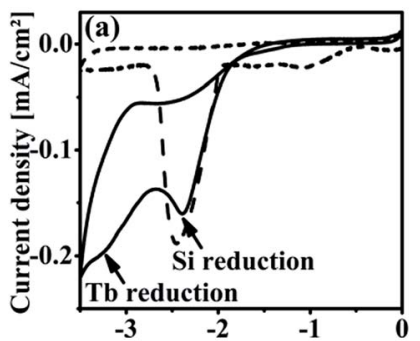

Potential IVI Vs Pt
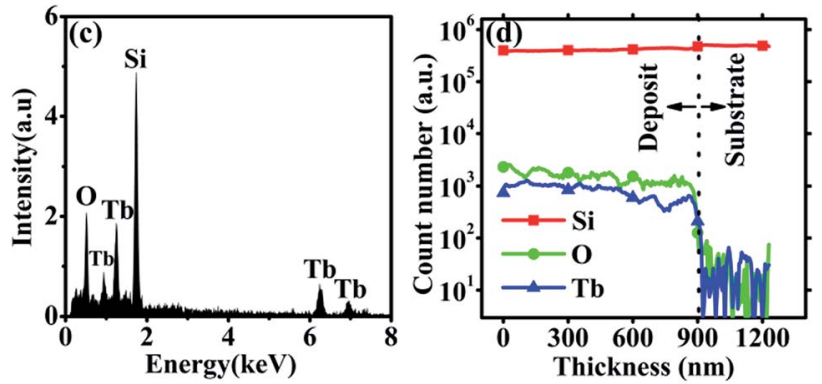

Fig. 4 (a) $\mathrm{CV}$ (scan rate of $10 \mathrm{mV} \mathrm{s}^{-1}$ ) of $\left[\mathrm{Py}_{1,4}\right] \mathrm{TFSI}$ with $0.01 \mathrm{M} \mathrm{SiCl}_{4}$ and $0.01 \mathrm{M} \mathrm{TbCl}_{3}$ (solid line) on $\mathrm{Si}(100)$ substrate vs. Pt. at $70^{\circ} \mathrm{C}$. The dashed line represents the $\mathrm{CV}$ of $\left[\mathrm{Py}_{1,4}\right] \mathrm{TFSI}$ with $0.01 \mathrm{M} \mathrm{SiCl}_{4}$ alone. (b) Top view SEM image of the Si/Tb thin film obtained by applying $-3.2 \mathrm{~V}$ vs. Pt. (c) The EDX spectrum obtained from the Si/Tb thin film. (d) SIMS depth profile of the deposit.

$\mathrm{SiCl}_{4}$ in $\left[\mathrm{Py}_{1,4}\right]$ TFSI (dashed line), it is clear that the Si reduction in the electrolytic system occurs at $-2.5 \mathrm{~V}$. The second peak shoulder observed at $-3.2 \mathrm{~V}$ corresponds to the reduction of the $\mathrm{Tb}^{3+}$ ions. In comparison with the $\mathrm{Si} / \mathrm{Er} \mathrm{CV}$ shown in Fig. 3a, the present $\mathrm{CV}$ is characterized by the presence of an apparent peak, instead of a shoulder, related to the $\mathrm{Si}^{4+}$ reduction. This is because of the lower rate of reduction observed for $\mathrm{Tb}^{3+}$ ions compared to $\mathrm{Er}^{3+}$ ions, so that the reduction waves corresponding to $\mathrm{Si}^{4+}$ and $\mathrm{Tb}^{3+}$ are not getting overlapped in the $\mathrm{CV}$. Also, it should be noted that the $\mathrm{Er}^{3+}$ reduction peak is observed at $-3 \mathrm{~V}$ while the peak corresponding to $\mathrm{Tb}^{3+}$ is slightly shifted and obtained at $-3.2 \mathrm{~V}$. No other significant reduction peaks are observed in the CV.

The co-deposition of $\mathrm{Si} / \mathrm{Tb}$ thin film was done potentiostatically onto $\mathrm{Si}(100)$ substrate by applying $-3.2 \mathrm{~V}$ for 1 hour at $70^{\circ} \mathrm{C}$. Fig. $4 \mathrm{~b}$ shows the top view SEM image of the obtained $\mathrm{Si} /$ $\mathrm{Tb}$ thin film. Contrary to the Si/Er thin film, the morphology of $\mathrm{Si} / \mathrm{Tb}$ thin film shows a flat and smooth deposit with few small cracks on the surface. It is worth comparing this with the SEM images of the pure RE metal deposits (Fig. $2 b$ and d) where the metallic Er thin film was observed to be rougher while the $\mathrm{Tb}$ thin film was very flat and smooth. It suggests that the nature of the RE metal can possibly influence the surface morphology of the deposit. Fig. 4c shows the EDX spectrum obtained from the $\mathrm{Si} / \mathrm{Tb}$ thin film. The spectrum gives the signatures for $\mathrm{Si}, \mathrm{Tb}$ and $\mathrm{O}$, indicating the successful incorporation of $\mathrm{Tb}$ in the $\mathrm{Si}$ thin film. Both $\mathrm{Si}$ and $\mathrm{Tb}$ contribute to the oxide content in the deposit as both the elements have strong affinity towards oxygen.

To confirm the homogeneity of the Tb incorporation in the thin film, SIMS depth profile analysis was performed. Fig. $4 \mathrm{~d}$ shows the depth profile of the $\mathrm{Si} / \mathrm{Tb}$ thin film. As evident from the spectrum, a quite uniform distribution of $\mathrm{Tb}$ and $\mathrm{Si}$ throughout the thickness of the deposit is observed. Additionally, the oxygen, which is bound to the $\mathrm{Si}$ and $\mathrm{Tb}$ here, is also found to be uniformly distributed along the thickness of the film. The SIMS depth profile confirms that the homogeneity and uniform chemical composition of the thin film are maintained throughout the growth.

\subsection{Concentration of $\mathrm{RE}(\mathrm{Er}, \mathrm{Tb})$ in Si thin films-tunability}

For the optical applications of the thin films, it is important to control the concentration of RE ions in the Si thin film. So, the possibility of controlling the RE concentration in the thin films by adjusting the electrochemical parameters has been studied.

Fig. 5 shows a schematic representation of a voltammogram showing the potential regimes to deposit different elements comprising the thin film. As can be seen in the figure, the voltammogram is divided into three potential regions. Region $\mathrm{A}$ $(-1$ to $-1.8 \mathrm{~V})$ represents the cathodic potential range in which no observable deposit is obtained by electrodeposition. Neither Si nor RE metals can be deposited at this potential range. Region $\mathrm{B}(-1.8 \mathrm{~V}$ to $-2.6 \mathrm{~V})$ represents the cathodic potentials in which pure $\mathrm{Si}$ is being electrodeposited and no significant contribution from the RE metal ions is detected. Region $\mathrm{C}$ $(-2.7 \mathrm{~V}$ to $-3.5 \mathrm{~V})$ in the voltammogram represents the potential range in which a co-deposition of Si and RE metals occurs, resulting in the Si/RE thin films.

Region C in Fig. 5 is of great importance as it gives the range of potentials in which RE metals are being co-deposited with Si. Herein it is shown that it is possible to easily control the RE ion content in the Si thin film by varying a single electrochemical parameter: the applied potential. Electrochemical co-deposition of Si and RE (Er and $\mathrm{Tb}$ ) was performed by applying different potentials in the range from $-2.7 \mathrm{~V}$ to $-3.5 \mathrm{~V}$.

The deposited thin films were analysed by EDX to check the composition of the deposits and for the estimation of the RE

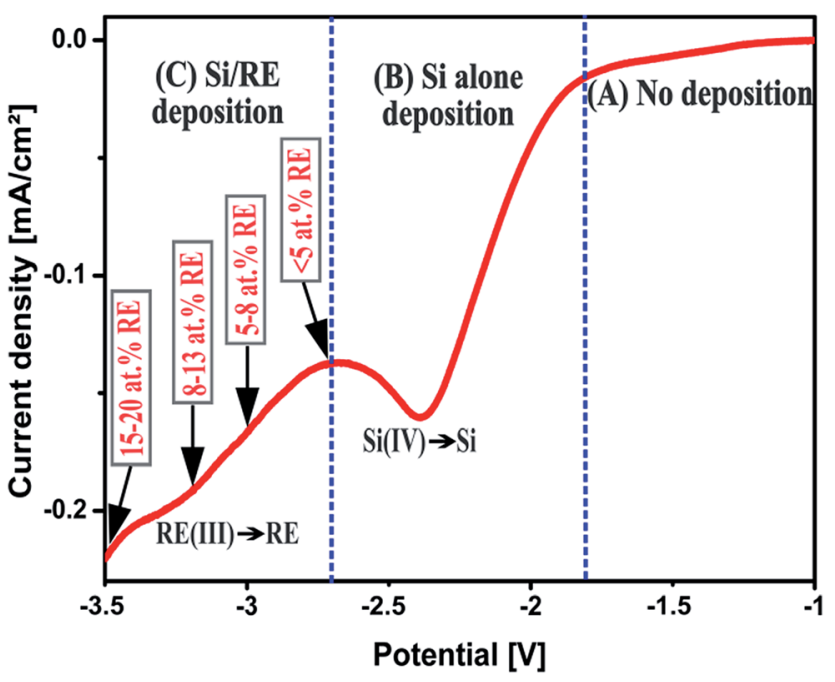

Fig. 5 Schematic representation of the cathodic potential regions for electrodeposition of pure Si and RE (Er, Tb) incorporated Si thin films. 
Table 1 Atomic percentage of RE (Tb, Er) metals incorporated in $\mathrm{Si}$ thin films deposited under different applied potentials

\begin{tabular}{ll}
\hline $\begin{array}{l}\text { Applied potential } \\
(V \text { vs. Pt) }\end{array}$ & $\begin{array}{l}\text { Atomic\% } \\
\text { of RE (Tb, Er) in deposit }\end{array}$ \\
\hline$-2.7 \mathrm{~V}$ & $<5 \%$ \\
$-3 \mathrm{~V}$ & $5-8 \%$ \\
$-3.2 \mathrm{~V}$ & $8-13 \%$ \\
$-3.5 \mathrm{~V}$ & $15-20 \%$
\end{tabular}

content in the thin films. Table 1 shows the dependence of RE content in the deposits with the applied potential. An applied potential of $-2.7 \mathrm{~V}$ resulted in Si thin films with very low $(<5$ at\%) RE content while the application of $-3.5 \mathrm{~V}$ gave deposits containing $15-20$ at $\%$ of RE. It is clear from Table 1 that the decrease of the applied potential leads to an increase of RE content in the thin films. It is important to point out here that the deposits obtained by applying $-3.5 \mathrm{~V}$ shows the inclusion of some impurities such as sulfur and carbon, which is due to the decomposition of the IL at higher negative potentials. However a thorough cleaning of the deposits by immersing it in ethanol for prolonged period resulted in decreasing the impurity levels to negligible values, meaning that the impurities are rather a surface contamination than being incorporated in the thin film. The above results show that the electrodeposition in RTILs offers not only a single step process for the incorporation of RE ions in $\mathrm{Si}$, but also provides an easy way to control the concentration of RE ions in the thin films.

\subsection{Optical properties}

For applications of the thin films in silicon-based light emitting systems, PL measurements were carried out on both $\mathrm{Si} / \mathrm{Er}$ and $\mathrm{Si} / \mathrm{Tb}$ thin films. The Si/Er thin film obtained by applying $-3 \mathrm{~V}$, having approximately 8 at\% of Er, was chosen for the initial PL experiments. The PL measurements were done with an excitation at $325 \mathrm{~nm}$. The black solid line in Fig. 6a shows the PL emission spectrum obtained from $\mathrm{Si} / \mathrm{Er}$ thin film at room temperature (RT). As evident from the spectrum, the PL gave a weak emission at $1530 \mathrm{~nm}$, which is characteristic of the ${ }^{4} \mathrm{I}_{15 /}$ ${ }_{2}{ }^{4} \mathrm{I}_{13 / 2}$ intra $4 \mathrm{f}$ transition in $\mathrm{Er}^{3+}$ ions in Si. The peak shoulder observed at $1545 \mathrm{~nm}$ is due to the stark splitting of the $\mathrm{Er}^{3+}$ energy levels resulting in the peak splitting of the luminescence band. ${ }^{42}$ In order to obtain an efficient PL emission, the Er incorporated Si materials has to be annealed under oxygen atmosphere, which is an important step to optically activate the $\mathrm{Er}^{3+}$ ions in the Si matrix. ${ }^{43-45}$ Therefore the Si/Er thin film was annealed at $650{ }^{\circ} \mathrm{C}$ under oxygen for 5 minutes. The red solid line in Fig. 6a shows the PL spectrum obtained at RT from the annealed Si/Er thin film. The PL gave a strong emission band at $1530 \mathrm{~nm}$ which is highly intense compared to the PL obtained from the non-annealed deposit. The high temperature annealing process enhances the oxygen diffusion into the $\mathrm{Si} / \mathrm{Er}$ thin film and leads to the formation of Er-O complexes, ${ }^{46}$ which act as efficient electronic traps. In addition, the complexation of Er with oxygen produces a solvation shell around the $\mathrm{Er}^{3+}$ ions,
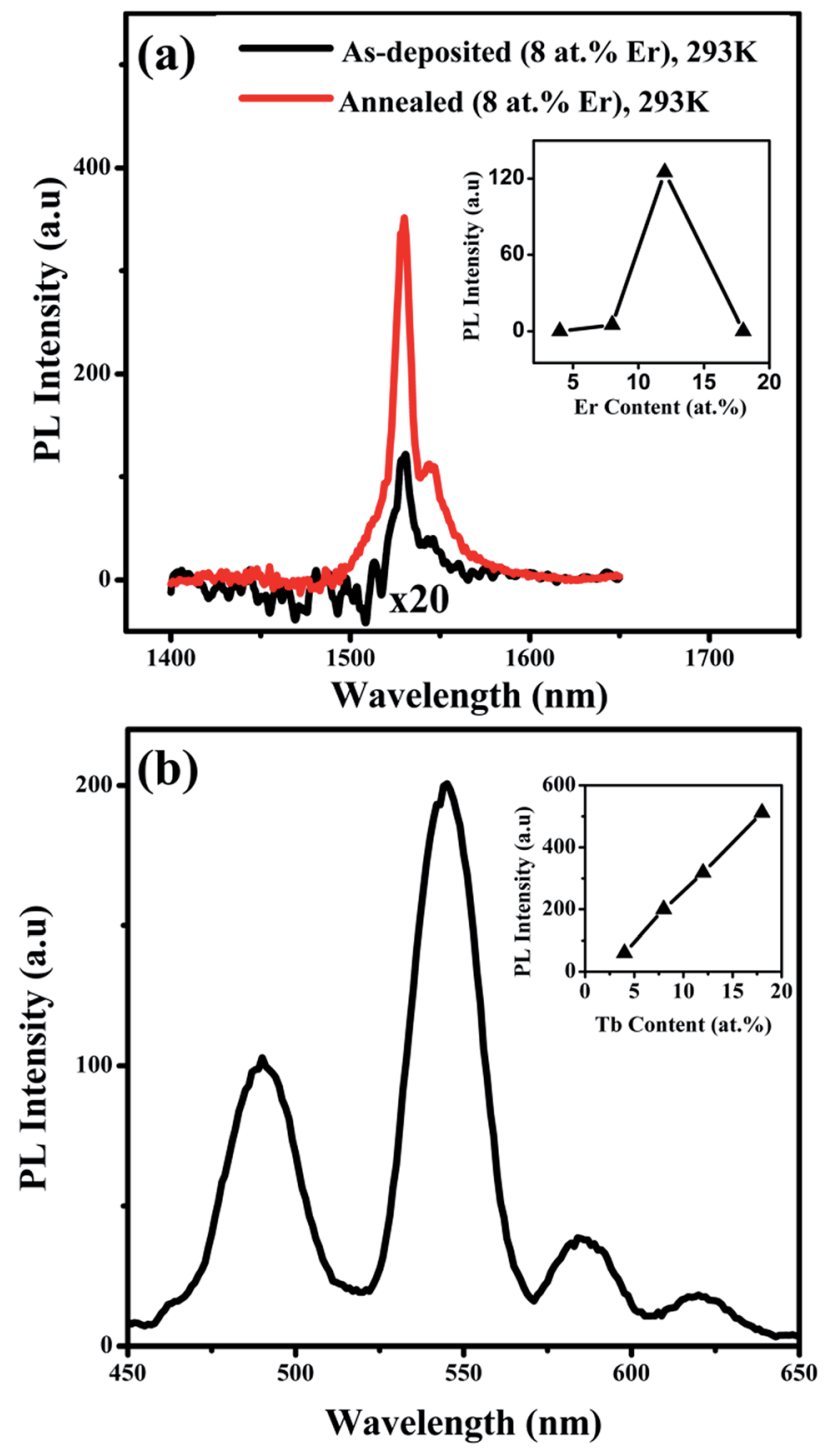

Fig. 6 (a) PL emission spectrum obtained at RT from as-deposited Si/ Er thin film (black) and PL emission spectrum at RT from annealed Si/Er thin film (red) using $325 \mathrm{~nm}$ laser source. The inset shows the variation of PL intensity at RT with the Er content in as-deposited Si/Er thin films. (b) The PL emission spectrum obtained at RT from the as-deposited (by applying $-3 \vee v s$. Pt) $\mathrm{Si} / \mathrm{Tb}$ thin film. Inset shows the variation of PL intensity at RT with the Tb content in the deposits.

thereby reducing the temperature quenching and at the same time promoting the radiative transitions ${ }^{47}$ Hence, an increased number of optically active emitting centres in the annealed Si/ Er thin film results in the higher luminescence intensity.

The inset of Fig. 6a shows the variation of the PL intensity at RT against Er content in the as-deposited thin films. No PL emission was detected from thin film with less than 5 at $\%$ of Er and a very weak PL was obtained from the deposit containing 8 at $\%$ of Er. The maximum PL intensity was obtained from the thin film containing 12 at $\%$ of Er in the deposit. The higher $\mathrm{Er}^{3+}$ concentrations may lead to the formation of micro-clusters of erbium silicates such as $\mathrm{Er}_{2} \mathrm{SiO}_{5}{ }^{48,49}$ or $\mathrm{Er}_{2} \mathrm{Si}_{2} \mathrm{O}_{7},{ }^{50,51}$ which are also luminescent in nature. However, it is observed that further 
increase in Er content than 12 at\% results in the quenching of the PL emission. The Si/Er thin film containing 20 at\% of Er did not give any detectable PL emission at RT. The higher concentration of $\mathrm{Er}$ in the thin film leads to the clustering of $\mathrm{Er}^{3+}$ ions which results in the concentration quenching of the luminescence due to the cross-relaxation processes. ${ }^{\mathbf{5 2 5 3}}$ It is important to note here that the low temperature electrodeposition in RTILs leads to the incorporation of Er in amorphous $\mathrm{Si}$ (a-Si) and not in crystalline $\mathrm{Si}(\mathrm{c}-\mathrm{Si})$ as in the case of most of the other growth techniques which could explain the observed intense emission signal. It is known that the a-Si offers better solubility for the $\mathrm{Er}^{3+}$ ions than the c-Si, and so a higher concentration of $\mathrm{Er}^{3+}$ can be achieved in a-Si compared to the cSi. ${ }^{\mathbf{1 , 5 2 , 5 4}}$ More importantly, it is reported that the a-Si clusters have a sensitizing effect on the $\mathrm{Er}^{3+}$ ions, ${ }^{55-57}$ which helps to improve the luminescence efficiency of $\mathrm{Er}^{3+}$ in Si. Therefore, the electrochemical co-deposition technique elaborated here is very important in this aspect as it gives the advantage of obtaining Er incorporated a-Si in a single step.

Contrary to the Si/Er thin film, no thermal annealing treatment is required for obtaining efficient $\mathrm{PL}$ from the $\mathrm{Si} / \mathrm{Tb}$ thin films because of the inherent affinity of $\mathrm{Tb}$ towards the oxygen. ${ }^{\mathbf{4 1}}$ The PL emission properties of the $\mathrm{Si} / \mathrm{Tb}$ thin films were studied by excitation with $325 \mathrm{~nm}$ wavelength laser source. The PL spectrum obtained at RT from $\mathrm{Si} / \mathrm{Tb}$ thin film deposited by applying $-3 \mathrm{~V}(8 \mathrm{at} \% \mathrm{~Tb})$ is shown in Fig. $6 \mathrm{~b}$. The spectrum shows emission bands in the visible wavelengths resulting from the radiative transitions between the intra $4 \mathrm{f}$ energy levels of the $\mathrm{Tb}^{3+}$ ions. In the spectra, four main PL bands can be identified where the most intense peak at $543 \mathrm{~nm}$ corresponds to the ${ }^{5} \mathrm{D}_{4^{-}}{ }^{7} \mathrm{~F}_{5}$ transition. The other observed transitions are ${ }^{5} \mathrm{D}_{4^{-}}{ }^{7} \mathrm{~F}_{6}$ $(486 \mathrm{~nm}),{ }^{5} \mathrm{D}_{4}{ }^{-}{ }^{7} \mathrm{~F}_{4}(583 \mathrm{~nm})$, and ${ }^{5} \mathrm{D}_{4}{ }^{-}{ }^{7} \mathrm{~F}_{3}(620 \mathrm{~nm})$. It is interesting to note here that no PL emission from the higher energy ${ }^{5} \mathrm{D}_{3}$ is detected from the thin films, as the cross relaxation processes produces an increase in the population of ${ }^{5} \mathrm{D}_{4}$ states at the expense of ${ }^{5} \mathrm{D}_{3}$ state. ${ }^{58}$ The stark splitting in the PL bands is not clearly identifiable from the spectrum because of the setup spectral resolution as the wavelengths corresponding to each stark level are very close (541 and $545 \mathrm{~nm}$ ) for the predominant PL band. The spectral shapes also depend on the local environment surrounding the $\mathrm{Tb}^{3+}$ ions, and such spectral shape is often observed in comparable materials. ${ }^{59,60}$

The inset of Fig. 6b compares the PL emission intensities at $\mathrm{RT}$ of $\mathrm{Si} / \mathrm{Tb}$ thin films with different $\mathrm{Tb}$ concentrations in the deposit. It is clear that the PL intensity increases with the increase in $\mathrm{Tb}$ content in the deposits. As evident from the graph, the deposit containing the lowest $\mathrm{Tb}$ content $(<5 \mathrm{at} \%)$ also shows a detectable PL emission. In contrast to the $\mathrm{Si} / \mathrm{Er}$ thin films, $\mathrm{Si} / \mathrm{Tb}$ thin film containing $15-20$ at $\%$ of $\mathrm{Tb}$ shows the highest PL intensity. The oxides $\left(\mathrm{Tb}_{2} \mathrm{O}_{3} \text { or } \mathrm{Tb}_{4} \mathrm{O}_{7}\right)^{61-63}$ of $\mathrm{Tb}$ formed at higher $\mathrm{Tb}^{3+}$ concentrations should have a significant contribution to the PL emission observed from the deposit. No concentration quenching effect is observed in the $\mathrm{Si} / \mathrm{Tb}$ thin films till 20 at\% of $\mathrm{Tb}$ content, which is the maximum $\mathrm{RE}$ content obtained by the current electrodeposition technique. The absence of concentration quenching phenomena in $\mathrm{Si} / \mathrm{Tb}$ deposits could be due to the high penetration depth of $\mathrm{Tb}$ in
$\mathrm{Si}^{64}$ and also to the high degree of oxidation of $\mathrm{Tb}$ in the deposit. It is reported that the presence of oxygen helps to reduce the segregation of $\mathrm{RE}$ in $\mathrm{Si}$ and makes the incorporation of it easier by forming RE-O complexes. ${ }^{65,66}$

\section{Conclusions}

In summary, a single step electrochemical method for the incorporation of RE ions (Er, Tb) in Si thin film using RTIL has been demonstrated for the first time. The electrodeposited $\mathrm{Si}$ / $\mathrm{RE}$ thin films are of good structural quality with uniform distribution of $\mathrm{RE}$ ions in the film. It is shown that the concentration of RE ions in the thin films can be easily tuned by adjusting the applied potential. Additionally, the electrodeposition of metallic Er and Tb from RTILs has been successfully demonstrated. The electrochemical co-deposition in RTIL results in the incorporation of $\mathrm{RE}$ ions directly in amorphous $\mathrm{Si}$, the combination of which found to be efficient for optical applications. The PL measurements show strong luminescence emission at $1.53 \mu \mathrm{m}$ from $\mathrm{Si} / \mathrm{Er}$ thin films and in the visible wavelengths (450-650 nm) from Si/Tb thin films. The intense PL emissions at room temperature confirm the quality of the electrodeposited thin films for applications in opto-electronics. The method described provides a simple and low cost alternative for the RE incorporation in Si. The obtained results also prove the versatility of the RTILs as a solvent for electrodeposition of semiconductors and RE incorporated semiconducting materials.

\section{Conflicts of interest}

There are no conflicts to declare.

\section{Acknowledgements}

The authors would like to acknowledge Region ChampagneArdenne, the DRRT Champagne-Ardenne and the European FEDER for the financial support through the Synapse project and their support of the Nano'mat platform.

\section{References}

1 A. J. Kenyon, Prog. Quantum Electron., 2002, 26, 225-284.

2 P. G. Kik and A. Polman, MRS Bull., 2013, 23, 48-54.

3 A. Polman, J. Appl. Phys., 1997, 82, 1-39.

4 G. Chang-xin, Z. Wei-ping and S. Chao-shu, J. Lumin., 1981, 24, 297-300.

5 J. D. B. Bradley and M. Pollnau, Laser Photonics Rev., 2011, 5, 368-403.

6 X. Huang, S. Han, W. Huang and X. Liu, Chem. Soc. Rev., 2013, 42, 173-201.

7 J. De Wild, A. Meijerink, J. Rath, W. Van Sark and R. Schropp, Sol. Energy Mater. Sol. Cells, 2010, 94, 1919-1922.

8 M. E. Castagna, S. Coffa, M. Monaco, A. Muscara, L. Caristia, S. Lorenti and A. Messina, Mater. Sci. Eng., B, 2003, 105, 8390. 
9 W. Gao, T.-k. Li, Y. Ono and S.-T. Hsu, J. Rare Earths, 2006, 24, 673-678.

10 B. Zheng, J. Michel, F. Y. G. Ren, L. C. Kimerling, D. C. Jacobson and J. M. Poate, Appl. Phys. Lett., 1994, 64, 2842-2844.

11 F. Namavar, F. Lu, C. H. Perry, A. Cremins, N. M. Kalkhoran and R. A. Soref, J. Appl. Phys., 1995, 77, 4813-4815.

12 S. Cueff, C. Labbé, J. Cardin, K. Hijazi, J.-L. Doualan, O. Jambois, B. Garrido and R. Rizk, Phys. Status Solidi C, 2011, 8, 1027-1032.

13 F. Gourbilleau, P. Choppinet, C. Dufour, M. Levalois, R. Madelon, C. Sada, G. Battaglin and R. Rizk, Phys. E, 2003, 16, 341-346.

14 F. Iacona, D. Pacifici, A. Irrera, M. Miritello, G. Franzò, F. Priolo, D. Sanfilippo, G. Di Stefano and P. G. Fallica, Appl. Phys. Lett., 2002, 81, 3242-3244.

15 A. Podhorodecki, J. Misiewicz, J. Wojcik, E. Irving and P. Mascher, J. Lumin., 2006, 121, 230-232.

16 J. E. Powell, Inorg. Chem., 1964, 3, 1070.

17 S. Zein El Abedin, N. Borissenko and F. Endres, Electrochem. Commun., 2004, 6, 510-514.

18 R. Al-Salman, S. Z. El Abedin and F. Endres, Phys. Chem. Chem. Phys., 2008, 10, 4650-4657.

19 N. Borisenko, S. Zein El Abedin and F. Endres, in Electrodeposition from Ionic Liquids, Wiley-VCH Verlag GmbH \& Co. KGaA, 2008, pp. 147-165.

20 M. Bechelany, J. Elias, P. Brodard, J. Michler and L. Philippe, Thin Solid Films, 2012, 520, 1895-1901.

21 T. Munisamy and A. J. Bard, Electrochim. Acta, 2010, 55, 3797-3803.

22 Y. Nishimura and Y. Fukunaka, Electrochim. Acta, 2007, 53, 111-116.

23 A. L. Bieber, L. Massot, M. Gibilaro, L. Cassayre, P. Taxil and P. Chamelot, Electrochim. Acta, 2012, 62, 282-289.

24 S. K. Cho, F.-R. F. Fan and A. J. Bard, Angew. Chem., Int. Ed., 2012, 51, 12740-12744.

25 G. M. Haarberg, L. Famiyeh, A. M. Martinez and K. S. Osen, Electrochim. Acta, 2013, 100, 226-228.

$26 \mathrm{H}$. Ohno, in Electrodeposition from Ionic Liquids, Wiley-VCH Verlag GmbH \& Co. KGaA, 2008, pp. 47-82.

27 J. Mallet, F. Martineau, K. Namur and M. Molinari, Phys. Chem. Chem. Phys., 2013, 15, 16446-16449.

28 J. Mallet, M. Molinari, F. Martineau, F. Delavoie, P. Fricoteaux and M. Troyon, Nano Lett., 2008, 8, 3468-3474.

29 F. Martineau, K. Namur, J. Mallet, F. Delavoie, F. Endres, M. Troyon and M. Molinari, IOP Conf. Ser.: Mater. Sci. Eng., 2009, 6, 012012.

30 D. Kowalski, J. Mallet, S. Thomas, A. W. Nemaga, J. Michel, C. Guery, M. Molinari and M. Morcrette, J. Power Sources, 2017, 361, 243-248.

31 A. M. Elbasiony, M. Olschewski, E. Abedin, S. Zein and F. Endres, ChemElectroChem, 2015, 2, 1361-1365.

32 A. Lahiri, M. Olschewski, T. Carstens, E. Abedin, S. Zein and F. Endres, ChemElectroChem, 2015, 2, 571-577.

33 K. Binnemans, Chem. Rev., 2007, 107, 2592-2614.

34 L. J. Small, J. M. Sears, T. N. Lambert, T. J. Boyle and R. F. Hess, RSC Adv., 2016, 6, 89564-89571.
35 L. J. Small, J. M. Sears, T. N. Lambert, T. J. Boyle and R. F. Hess, RSC Adv., 2016, 6, 89564-89571.

36 T. Kimura, A. Yokoi, H. Horiguchi, R. Saito, T. Ikoma and A. Sato, Appl. Phys. Lett., 1994, 65, 983-985.

37 M. Gong, J. Shi, W. Wong, K. Shiu, W. Zheng and K. Cheah, Appl. Phys. A: Mater. Sci. Process., 1999, 68, 107-110.

38 G. Mula, T. Printemps, C. Licitra, E. Sogne, F. D'acapito, N. Gambacorti, N. Sestu, M. Saba, E. Pinna and D. Chiriu, Sci. Rep., 2017, 7, 5957.

39 B. Gelloz, R. Mentek and N. Koshida, Phys. Status Solidi C, 2012, 9, 2318-2321.

40 N. K. Shah, R. K. Pati, A. Ray and I. Mukhopadhyay, Langmuir, 2017, 33, 1599-1604.

41 G. L. P. Berning, H. C. Swart and B. de Witt, Appl. Surf. Sci., 1993, 64, 1-7.

42 H. Isshiki, A. Polman and T. Kimura, J. Lumin., 2003, 102103, 819-824.

43 S. Coffa, G. Franzò, F. Priolo, A. Polman and R. Serna, Phys. Rev. B: Condens. Matter Mater. Phys., 1994, 49, 16313-16320.

44 A. Polman, G. N. v. d. Hoven, J. S. Custer, J. H. Shin, R. Serna and P. F. A. Alkemade, J. Appl. Phys., 1995, 77, 1256-1262.

45 A. R. Zanatta and F. L. Freire, Phys. Rev. B: Condens. Matter Mater. Phys., 2000, 62, 2016-2020.

46 P. Favennec, H. l'Haridon, D. Moutonnet, M. Salvi and M. Gauneau, Jpn. J. Appl. Phys., Part 1, 1990, 29, L524.

47 J. Michel, J. Benton, R. Ferrante, D. Jacobson, D. Eaglesham, E. Fitzgerald, Y. H. Xie, J. M. Poate and L. Kimerling, J. Appl. Phys., 1991, 70, 2672-2678.

48 H. S. Kamineni, V. K. Kamineni, R. L. Moore, S. Gallis, A. C. Diebold, M. Huang and A. E. Kaloyeros, J. Appl. Phys., 2012, 111, 013104.

49 J. Zheng, W. Ding, C. Xue, Y. Zuo, B. Cheng, J. Yu, Q. Wang, G. Wang and H. Guo, J. Lumin., 2010, 130, 411-414.

50 M. Miritello, P. Cardile, R. L. Savio and F. Priolo, Opt. Express, 2011, 19, 20761-20772.

51 M. Miritello, R. Lo Savio, F. Iacona, G. Franzò, A. Irrera, A. M. Piro, C. Bongiorno and F. Priolo, Adv. Mater., 2007, 19, 1582-1588.

52 D. J. Eaglesham, J. Michel, E. A. Fitzgerald, D. C. Jacobson, J. M. Poate, J. L. Benton, A. Polman, Y. H. Xie and L. C. Kimerling, Appl. Phys. Lett., 1991, 58, 2797-2799.

53 D. S. Lee, J. Heikenfeld, A. J. Steckl, U. Hommerich, J. T. Seo, A. Braud and J. Zavada, Appl. Phys. Lett., 2001, 79, 719-721. 54 T. Oestereich, C. Swiatkowski and I. Broser, Appl. Phys. Lett., 1990, 56, 446-447.

55 G. W. Adeola, H. Rinnert, P. Miska and M. Vergnat, J. Appl. Phys., 2007, 102, 053515.

56 G. Franzò, S. Boninelli, D. Pacifici, F. Priolo, F. Iacona and C. Bongiorno, Appl. Phys. Lett., 2003, 82, 3871-3873.

57 A. Meldrum, A. Hryciw, A. N. MacDonald, C. Blois, T. Clement, R. DeCorby, J. Wang and Q. Li, J. Lumin., 2006, 121, 199-203.

58 H. Amekura, A. Eckau, R. Carius and C. Buchal, J. Appl. Phys., 1998, 84, 3867-3871.

59 M. Klak, G. Zatryb, J. Wojcik, J. Misiewicz, P. Mascher and A. Podhorodecki, Thin Solid Films, 2016, 611, 62-67. 
60 B. Kaleli, M. Kulakci and R. Turan, Opt. Mater., 2012, 34, 1935-1939.

61 L. Li, S. Wang, G. Mu, X. Yin and L. Yi, Sci. Rep., 2017, 7, 42479.

62 H. Choi, J. H. Kim, S.-s. Yi, B. K. Moon and J. H. Jeong, Journal of Alloys and compounds, 2006, 408, 816-819.
63 S. V. Belaya, V. V. Bakovets, I. P. Asanov, I. V. Korolkov and V. S. Sulyaeva, Chem. Vap. Deposition, 2015, 21, 150-155.

64 D. E. Nazyrov, Semiconductors, 2006, 40, 630-631.

65 J. S. Custer, A. Polman and H. M. v. Pinxteren, J. Appl. Phys., 1994, 75, 2809-2817.

66 R. Serna, M. Lohmeier, P. M. Zagwijn, E. Vlieg and A. Polman, Appl. Phys. Lett., 1995, 66, 1385-1387. 